\title{
Pre-operative Evaluation of Adult Patients Undergoing Elective Non-cardiac Surgery in Lithuanian Hospitals
}

Jaremko I. ${ }^{1}$, Stremaityte V. ${ }^{2}$, Gudaityte J. ${ }^{1}$

${ }^{1}$ Department of Anaesthesiology, Lithuanian University of Health Sciences,

Kaunas, Lithuania;

2 Department of Emergency Medicine, Vilnius University, Vilnius, Lithuania.

Background and Goal of Study: The aim of this study was to assess the extent of preoperative evaluation of adult patients undergoing elective non-cardiac surgery in Lithuanian hospitals (LH) compared to ESA guidelines [1].

Materials and Methods:

$\left.\left.\geqslant \begin{array}{c}\text { Approved by } \\ \text { local Ethics } \\ \text { Committe }\end{array}>\begin{array}{c}\text { Functioning } \\ \text { Departments of } \\ \text { Surgery }\end{array}>\begin{array}{c}\text { Mailed to } 42 \\ \text { hospitals }\end{array}>\begin{array}{c}\text { Answered by } \\ \text { anaesthesiologists }\end{array}\right\rangle \begin{array}{l}\text { Response rate } \\ 71.4 \%\end{array}\right\rangle$

Results and Discussion:

ESA Preoperative Evaluation Guidelines

Should be performed

Pre-operative evaluation performed Should be carried out with sufficient time before surgery

Standardized questionnaires

Screening for DMV and difficult intubation

Should be conducted in all patients (A). Assessment needs the combination of different validated evaluation criteria (A) before the scheduled procedure (D) May be helpful in a variety of situations (D)

By an anaesthesiologist (D), by either trained nurses (C) or anaesthesia trainees (D)
$39.2 \%$ done $<2 \mathrm{~h}$ before surgery

76.6\% standardized questionnaires

96.6\% screening is done. History of previous anaesthesia's evaluated $96.6 \%$, assessment of Mallampati class - $96.6 \%$, thyromental distance

- $72.4 \%$, head and neck mobility - $75.9 \%$, length of neck - $82.8 \%$, thickness of neck - 3.4\%, interincisor distance (mouth opening) - 100\%, jaw protrusion - $86.2 \%$, BMI - $75.9 \%$, age $58.6 \%$, snoring and sleep apnoea $-51.7 \%$, sex $31 \%$

Include: clinical evaluation, Berlin or STOP Pre-operative assessment of obese patients

$\begin{array}{lr}\text { questionnaire, ECG, } & \text { polysomnography } \\ \text { and/or oximetry, } & \text { glucose/HbA1C }\end{array}$ concentrations (D)

Routine use is not recommended (D). Correction of haemostasis decreases perioperative bleeding (D). A bridging management is recommended in high-risk patients under oral anticoagulation (A)

It is recommended start early (at least 6 to

8 weeks prior surgery, 4 weeks at a Smoking cessation recommended $10 \%$ minimum) (B)

Should be continued peri-operatively (A)

Should be asked and discontinued 2 weeks prior to surgery (D)

Herbal drugs

Antidepressant

treatment

antipsychotic medication
$72.4 \%$ continued

Clinical evaluation - 100\%, Berlin/STOP questionnaires - 3.3\%, ECG - 90\%, polysomnography/oximetry - $6.6 \%$, glucose $/ \mathrm{HbA} 1 \mathrm{C}-96.6 \%$ for obese patients

$86.6 \%$ done routinely; abnormal state treated in $100 \%$ of cases; bridging management continued $100 \%$ of cases

Asked $-44.8 \%$, stopped $-20.6 \%$

93.1\% antidepressants, $100 \%$ antipsychotic continued

\section{Conclusions:}

1) Preoperative evaluation in Lithuanian hospitals is done by a doctor anaesthesiologist, mostly 2 hours or less before the surgery, using standardized questionnaires.

2) Patients with comorbidities and/or taking medication before surgery are evaluated and prepared according to the ESA recommendations in most of LHs. However, some recommendations related to smoking cessation, the assessment of obese patients, usage of herbal preparations, are performed in a small number of LHs.

3) Airway evaluation is done in most of LHs according to ESA recommendations.

References: 1. De Hert S, Imberger G, Carlisle J, et al. Preoperative evaluation of the adult patient undergoing non-cardiac surgery: guidelines from the European Society of Anaesthesiology. Eur J Anaesthesiol 2011; 28:684 - 722. 